Dr. Fox. rightly refers to cauterization in corneal ulceration as an epochal step in ophthalmic surgery, which assures its author a permanent place in medical history, it seems to me very desirable that ThE Journal should correct the error as to the originator of this procedure.

It was Dr. Martinache, a practicing oculist of San Francisco, who was the first to treat corneal ulcer successfully with the active cautery (as well as iris prolapse and keratitis interstitialis). He published his method, "Ulcers of the Cornea, Treated by the Actual Cautery," in the Pacific Medical and Surgical Journal, Nov. 18, 1873, p. 294; also "De l'emploi du cautère actuel dans les maladies des yeux, et principalement dans les ulcères de la cornée," Annalcs $d^{\prime}$ 'oculistique, $1878, \mathbf{8 0}, 21$. It is true, however, that the procedure was taken notice of and came into general use only after the publication of Gayet in 1877.

On the other hand, it sounds rather naive for a writer in the American Encyclopedia for Ophthalmology to remark rather disparagingly that since the active cautery had been in general use for a long time before it must be presumed that it may have been used in this field as well. The answer to that is of course that there is no record to that effectand there are other eggs of Columbus-and may the wholesome fear for those precious, unique, odd millimeters of pellucid tissue never die!

$$
\text { C. S. G. NAgel, M.D., San Francisco. }
$$

\section{DRAFTING PHYSICIANS}

To the Editor:-Referring to your editorial of Aug. 11, 1917, on the selective draft for physicians, it is quite possible that the prevalence of "hysteria" with reference to the providing of adequate medical service for the new Army would $b$ reduced if the acquiring of sufficient physicians was done by such a selective draft as would take into consideration both the individual's wishes, his obligation to community or family, and the government's need for his services.

The editorial of August 11 disregards the points which alone make a selective draft desirable. It is not the absolute number of tmen that has been, or can be, obtained for the medical service which is causing, or has caused, anxiety on the part of the government, or "hysteria" on the part of the Committee of National Defense or of the individual physician.

The figures quoted in the editorial are correct, but they speak of physicians without qualification as to the age or fitness of these men for active military service.

There are three things that make this selective draft of physicians particularly desirable: (1) the best protection of the government's needs; (2) the protection of the community, which should be assured adequate medical attendance, and (3) the protection of the physician himself from decisions which perhaps may have been made at times unwisely through the very "hysteria" referred to above.

The first, the needs of the government, of course includes the second and third. The economical use of the medical material is of first importance, if this is to be a long war. The continuance of the output of doctors through the conservation of medical students and teachers, and the maintenance of the health of the community at large are as important as the immediate providing of a given namber of physicians for military service.

Regarding the number of men available: While the figures given in THE Journal are satisfactory, if looked at on the basis of the present law providing seven medical men for 1,000 troops, they immediately become quite unsatisfactory if looked at in the light of the probable ultimate decision to provide twenty medical officers per thousand troops. It will be difficult to obtain the latter number by the volunteer system without falling into the same error that has brought about so much local distress in Great Britain through lack of medical attention at home.

Second, protection of the community: Under the volunteer system there can be no control exercised over the reduction of medical men in certain districts to a number fewer than necessary for proper care in that community. If the number of men taken from a given locality depends solely on the decision of the individual physician, as to whether he would like to, or should, enter military service, some localities may be devastated, others may be very little affected.

An even distribution of the remaining talent is impossible. Under the selective draft of physicians this matter would be properly covered.

Third, the protection of the physician himself: It must be admitted that the decision of many men as to the relative importance of military or home service has been wrongly made, through the feeling that their example makes it necessary for them to enlist, in spite of the knowledge that their professional capacity makes their services particularly desirable in nonmilitary affairs.

A selective draft puts the individual on record as to his qualifications and obligations, but leaves his disposition to the proper authorities. It offers the great asset to the individual of the sense of direct service, whether his orders involve civilian or military duties. The "tremendous sacrifices" referred to in the summary of the editorial would probably be reduced to a minimum under the action of a selective draft, making the most economical use of medical material at hand, without "coercion," without "threats," but with a view of sending the man best fitted for the service into the Army, and conserving all nonmilitary interests to the country by holding in their proper places men who should not go, but who certainly do go through their anxiety to avoid any possible appearance of selfish avoidance of military duty.

Herbert B. Wilcox, M.D., New York.

\section{Queries and Minor Notes}

Anonymous Communications and queries on postal cards will not be noticed. Every letter must contain the writer's name and addess, but these will be omitted, on request.

\section{ACUTE DIARRHEA IN INFANTS}

To the Editor:-In The Journal, Aug. 25, 1917, p. 645 , it is stated that lactose in from 3 to 5 per cent. solution in water should be given. Will you please explain to me why, how much, and how it should lee given? Also please explain the advantage of starch water. Also please explain the methods of administration, indications for, and advantages of giving glucose. If this is published please withhold my name.

A. W. P.

ANSwer.-Many infants suffering from acute diarrhea die of acidemia, especially if the diarrhea is accompanied by vomiting. Hence to prevent acidemia a little sugar or starch is advisable during the starvation, or insufficient diet, period. If acidemic symptoms are present, starch and sugar are essential, and if they cannot be retained by the stomach, small colon injections of these substances are advisable. Furthermore, sugar in any form is a food and a stimulant, and it will even strengthen a weak heart in prostration.

Lactose (milk sugar) is better than sucrose (cane sugar) because it is less sweet and is less apt to cause fermentation in the stomach and intestine; it is a diuretic also, and in these diarrheal conditions the kidneys act very sluggishly. A 3 to 5 per cent. solution of lactose in water (or in a thin cereal gruel if such a food is advisable) in 1 or 2 ounce doses may be given at two or three hour intervals. The little patient should receive plain water between these feedings, unless more food is advisable.

Starch water acts like any other bland starchy food; in other words, it is a food. Warm starch solutions are very soothing to every inflamed mucous membrane, whether it is the mouth, the throat, the gullet, the stomach, the intestine or the rectum.

Glucose (grapc sugar) is not so sweet as sucrose, but it is not so well tolerated as lactose, as it is rather irritant. The glucose of the Pharmacopeia is a syrupy liquid, very soluble in water.

In acidosis conditions, glucose is valuable as a nutrient enema, given either in water or in milk. A 3 to 10 per cent. solution, or even stronger, in milk or in physiologic sodium chlorid solution may be given by the rectum. For a child, 2 or 3 ounces, repeated every six hours for a few times, would be a fair dose. In older patients the rectal drip method is valuable.

When glucose is absorbed into the blood it is theoretically more quickly ready for muscle use than are other sugars; 